\title{
Evaluation of random parking layout SBA mall using integer linear programing
}

\author{
Prima Denny Sentia ${ }^{1,2,{ }^{*}}$, Nissa Prasanti $^{3}$, Andriansyah ${ }^{1,2}$ and Rizfa Ramadhani Pulungan ${ }^{1}$ \\ ${ }^{1}$ Laboratory of Industrial Computation and Optimization, Syiah Kuala University, 23111 Aceh, \\ Indonesia \\ ${ }^{2}$ Industrial Engineering Department, Syiah Kuala University, 23111 Banda Aceh, Indonesia \\ ${ }^{3}$ Industrial Engineering Department, Teuku Umar University, 23612 Meulaboh, Indonesia
}

\begin{abstract}
SBA Mall is the largest shopping center in Aceh. The number of vehicles visitors reach 1.300 units of cars every day so it takes parking space that can accommodate visitor's vehicles. Setting the parking is very important to produce parking space with a lot of capacity, as well as comfortable and safe for visitors. The problem that arises today is the application of the parking rules that have not been applied in the parking area of SBA Mall. Integer Linear Programming (ILP) in this research is used to model parking layout by planning three scenarios that is based on the actual condition, the width of alley according to the Decree of Directorate General of Land Transportation without pedestrian facility, and all the size of parking lot fully according to the Decree mentioned above. The result shown that the total unit of parking space (UPS) based on the first scenario is 119 UPS, the second scenario is 94 UPS and in the third scenario is 97 UPS.
\end{abstract}

\section{Introduction}

Currently, the vehicle is one of the most important and very useful thing in human life. Every time the vehicle is used for a trip, it always starts and ends in the parking lots, so it will increase vehicle volume and will have an impact in the parking space. Parking is one of the most important elements of the transportation system. Management of parking lots is necessary to make parking more convenient and safe for vehicle users.

Lack of existing parking space capacity is a challenge to utilize the parking areas more efficient. Design, size and location to determinate of parking space have many variations. The more efficient the utilization of parking space, the higher capacity it will produce. Many factors affect the design of parking such as the number of vehicles that need to be accommodated, parking angle, the system of circulation in the parking, and the size of the vehicle [1].

\footnotetext{
Corresponding author: primadennysentia@unsyiah.ac.id
} 
The parking area is designed according to the appropriate parking pattern angle. Parking spaces or parking lots are designed with different angles such as $45^{\circ}, 60^{\circ}$, and $90^{\circ}$ [2]. The most common angle used for parking is $60^{\circ}$ because it provides a wide traffic lane so the vehicle maneuvering time is faster and easier. The $45^{\circ}$ angle is applied when the parking lots limit the size of the hallways and available parking spaces. With a narrow alley, maneuvering the vehicle is easier. The $90^{\circ}$ angle provides the most parking space for a particular area but have a high difficulty level when entering and leaving parking space. Due to the difficulty of entering and leaving the parking spaces, the $90^{\circ}$ angle parking is only recommended for daytime parking such as university parking areas or workplace parking areas.

One of the appropriate models to determine the optimal angle is Model Integer Linier Programming (ILP). ILP is a mathematical model that can be used to find all possible solutions of the problem. Application of ILP in case of parking capacity optimization has been done by [1] and it is an extension of linear programming that some or all the variables in the optimization problem are restricted to take only integer values [3].

SBA Mall is the largest shopping center in Banda Aceh. Increasing number of visitors caused the parking area of private vehicle Mall to be full. The current parking lot layout is mostly designed using $90^{\circ}$ angles with one-way circulation paths and random parking lots. With such a layout visitors are difficult to park their vehicles. The current size of parking space is also not in accordance with the standards technical guidance of the implementation parking facilities by [4]. The upright parking pattern $\left(90^{\circ}\right)$ is most efficient in terms of utilization of available space, but there should be a wider aisle available so the driver does not have difficulty when doing parking maneuvers while the angled parking pattern is more superior in term of ease of parking maneuver, but less efficient in terms of space used [5].

Based on the problems that have been described, it is necessary to evaluate the design of parking spaces and capacity SBA Mall by using mathematical model. This study was conducted to evaluate and determine the angle of parking space, the width of parking space, and the width of the alley according with the conditions [4] so it will result a safe and convenient layout for visitors..

\section{Methodology}

\subsection{Research Needs Identification}

This section will explain the stages of research that has been done. The initial stage is to identify the research needs. Problem identification is done by observing the current situation and condition of car parking area SBA Mall and literature study. Direct observation is made to see the initial layout along with the size of the parking lot and literature study is also conducted to obtain mathematical models and methods of solving the relevant problems so the method will get the best solution to answer the problem. After the problem is identified, the goals and benefits are set to be obtained from the results of research. Figure 1 shows division drawing and initial layout of the parking area. 


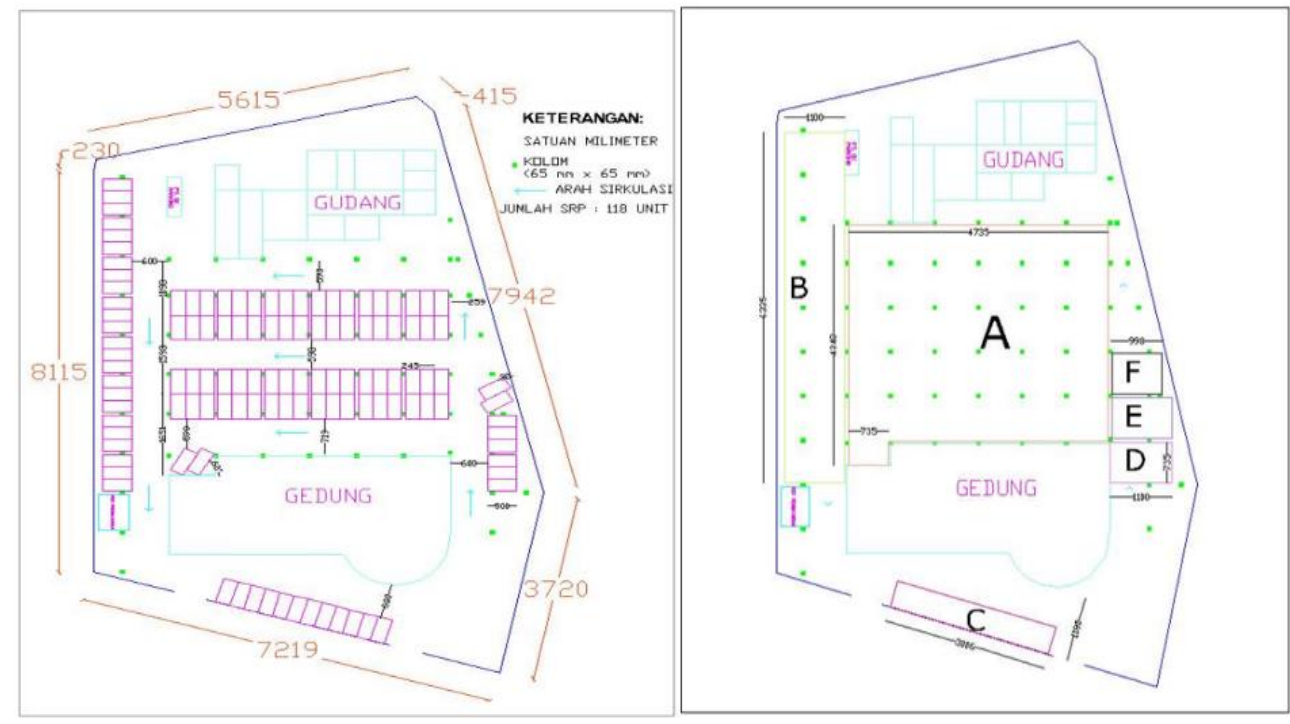

Fig. 1. Existing Layout (left); Division of area Layout (right)

\subsection{Establishment of Mathematical Model Parking Space Unit}

The calculation of coefficients used is based on the equation of parking space determination by [6] with the determinant of parking space width and alley. The coefficient of mathematical model ILP determined based on three types of scenarios formed for the proposed layout. The three scenarios formed for the evaluation of the parking layout of SBA Mall is:

a. The first scenario is based on the initial conditions with a width of 2.45 meters, the aisle according to the initial conditions that is for $90^{\circ}$ and $60^{\circ}$ angles is 5.98 meters, and for $45^{\circ}$ and $30^{\circ}$ angle is 3.5 meters.

b. The second scenario is based on a combination between initial conditions and the Technical Guidelines for the Implementation of Parking Facility according to the Directorate General of Land Transportation. Size The width of the parking space follows the initial conditions that is 2.45 meters. The size of the alley follows the standards of the Directorate General of Land Transportation for $30^{\circ}$ and $45^{\circ}$ angle is 3.5 meters and for $60^{\circ}$ is 5.1 meters and for $90^{\circ}$ is 6 meters.

c. The third scenario is based on the standards of the Directorate General of Land Transportation using a pedestrian facility that has similarities with second scenario but at an angle of $90 \mathrm{o}$ the alley size is 6.5 meters

\subsection{Mathematical Model Processing Unit of Parking Space Based on Scenario}

After determining the mathematical model of ILP for the determination of unit parking space, the next step is to process the mathematical model based on predetermined scenario using LINGO 11 application. LINGO is comprehensive software designed to develop and solve mathematical models for optimization more easily and more 
efficiently [7]. Process of Mathematical model for the parking area is divided into several sections, namely zone $\mathrm{A}$, zone $\mathrm{B}$, zone $\mathrm{C}$, zone $\mathrm{D}$, zone $\mathrm{E}$, and zone $\mathrm{F}$.

\subsection{Layout Optimization}

Each area has the same variables decision and objective function while the constraint function is different. Therefore, after obtaining the layout optimization based on each scenario, the result analysis was done which then becomes the evaluation material for the parking layout of SBA Mall.

\section{Results and Discussion}

\subsection{Mathematical Model of Parking Space Unit}

The entire parking area uses the ILP mathematical model where the length and width of the parking lot refer to [1]. Each possible parking row has the possibility of parking angle of $30^{\circ}, 45^{\circ}, 60^{\circ}$, and $90^{\circ}$. To facilitate the creation of a mathematical model to determine the capacity of parking space unit, then the division of the line shown by Figure 2.

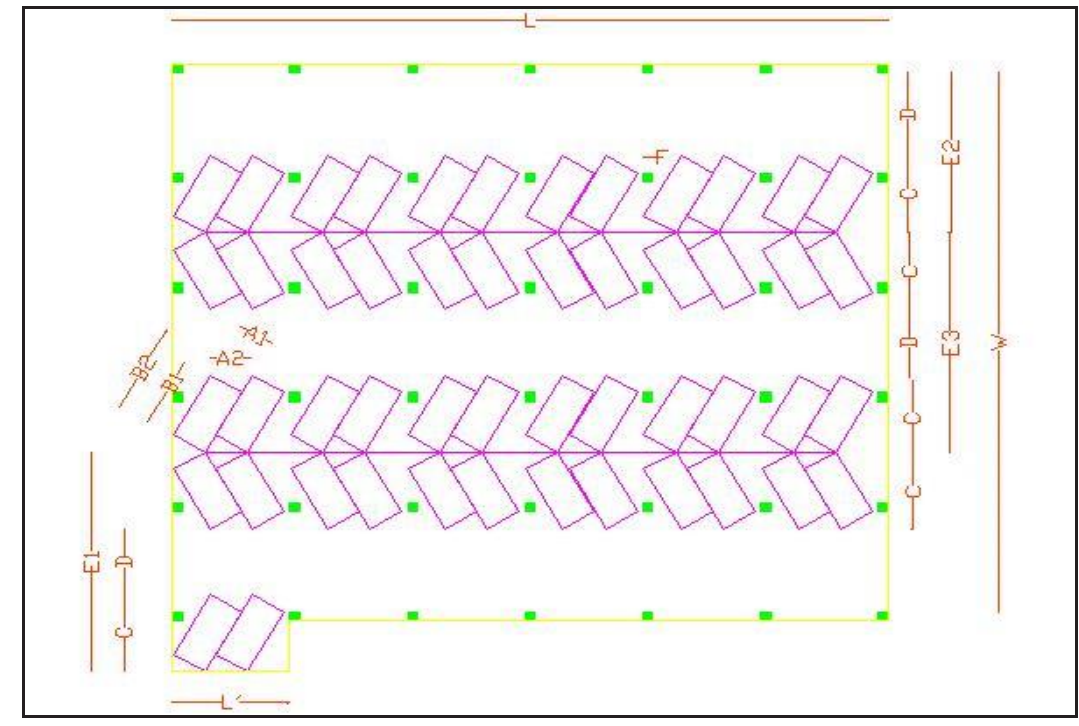

Fig. 2. Establishment of Parking Lot and Parking Space Unit

\section{Explanation:}

$A_{1} \quad$ : width of vehicle

$A_{2} \quad:$ width of vehicle in rows $=\frac{A_{P}}{\sin \theta}$

$B_{1} \quad$ :length of vehicle

$B_{2} \quad:$ length of vehicle in rows $=\left(\frac{A_{I}}{\tan \theta}\right)+B_{I}$

$C \quad$ :parking line width

D : aisle 
$E_{1} \quad$ : width of full exterior rows $=D+(2 \times C)$

$E_{2} \quad$ : width of exterior rows $=C+D$

$E_{3} \quad$ : width of full interior rows $=D+(2 \times C)$

$W \quad$ :total parking space width

$L \quad$ : total parking space length

$L^{\prime} \quad$ : length of second parking space

Based on Figure 2 can be modeled the purpose function in this research is to maximize the unit of parking space of SBA Mall based on parking angle as follows :

1. Decision Variables

Number of parking rows: $X\left(\operatorname{ep}_{,}\right), X\left(\theta_{\theta}, 9\right), X(i p, \theta)$; number of UPS : $n\left(\operatorname{sp}_{\theta}\right), n\left(\epsilon_{0}, 9\right), n(i p, \theta) ; \theta=30^{\circ}, 45^{\circ}, 60^{\circ}$, dan $90^{\circ}$.

2. Objective function:

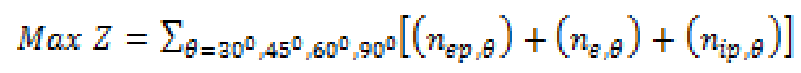

3. Constraints

a. Width of the whole $\mathrm{W}$

$$
\sum_{\theta=a 0^{0}, 45^{0} 60^{0}, 90^{0}}\left[\left(E_{1} X_{6 p, \theta}\right)+\left(E_{2} X_{\theta_{2}, \theta}\right)+\left(E_{2} X_{i p, \theta}\right)\right] \leq W
$$

b. Width of full exterior rows

$$
\sum_{\theta=30^{0}, 45^{0}, 60^{0}, 90^{\circ}}\left[E_{1} X_{\theta_{i} \theta}\right] \leq E_{\text {Full Exterior }}
$$

c. Width of full interior rows

d. Width of exterior rows

$$
\sum_{\theta=90^{\circ} 45^{\circ} 60^{0} \alpha 90^{\circ}}\left[E_{2} X_{\theta_{\alpha} \theta}\right] \leq E_{\text {Full Interior }}
$$

e. Length of full exterior rows

$$
\sum_{\theta=90^{0}, 45^{0}{ }_{2} 60^{0}, 90^{0}}\left[E_{a} X_{\theta_{\lambda} \theta}\right] \leq E_{\text {Exterior }}
$$

$$
\left(A_{2} n_{\operatorname{ep}, \theta}\right)-\left(L+L^{b}\right) X_{\operatorname{sp}_{1} \theta}-8 F \leq 0
$$

f. Length of exterior rows

$$
\left(A_{2} n_{\theta_{e} \theta}\right)-L X_{\theta_{2} \theta}-7 F \leq 0
$$

g. Length of interior rows

$$
\left(A_{2} n_{i p_{2} \theta}\right)-2 L X_{i p_{i} \theta}-7 F \leq 0
$$

h. Non negative constraint

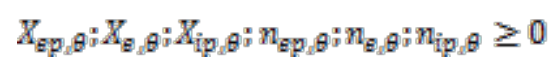

Explanation:

Z

: Totalnumber UPS

$\left.X f_{\text {ep, },}\right)$ : number of full exterior rows with $\theta$

$\left.X]_{\text {eg, }}\right] \quad$ : number of exterior rows $\theta$

$X f_{i p, \theta)}$ : number of fullinterior rows $\theta$

$n /$ eq, $\theta$ : number UPS of full exterior rows with $\theta$

$n / Q$, : number UPS of exterior rows with $\theta$

$n(i, \theta)$ : number UPS of full interior rows with $\theta$

$E \quad$ : width of the whole of area

$F \quad$ : length of blocked space 


\subsection{Results of Parking Area Optimization}

This study uses a random parking layout, so that the mathematical model generated more than the research conducted [1] using a square parking layout. Because of its random shape, it must be separated into several areas. Optimal results from each area will be combined into an optimal solution. The results of the ILP mathematical model processing using the LINGO application to optimize the parking area based on all the scenarios listed in Table 1.

Table 1. Recapitulation of ILP Modeling Results

\begin{tabular}{|c|c|c|c|c|c|c|c|c|c|c|c|c|c|}
\hline \multirow{2}{*}{$\begin{array}{c}\text { Are } \\
\mathrm{a}\end{array}$} & \multirow{2}{*}{ Rows } & \multicolumn{4}{|c|}{ First Scenario } & \multicolumn{4}{|c|}{ Second Scenario } & \multicolumn{4}{|c|}{ Third Scenario } \\
\hline & & $30^{\circ}$ & $45^{\circ}$ & $60^{\circ}$ & $90^{\circ}$ & $30^{\circ}$ & $45^{\circ}$ & $60^{\circ}$ & $90^{\circ}$ & $30^{\circ}$ & $45^{\circ}$ & $60^{\circ}$ & $90^{\circ}$ \\
\hline \multirow{3}{*}{ A } & $\begin{array}{c}\text { Full } \\
\text { exterior }\end{array}$ & 0 & 0 & 0 & 21 & 10 & 0 & 0 & 0 & 0 & 14 & 0 & 0 \\
\hline & Exterior & 0 & 0 & 0 & 36 & 0 & 0 & 15 & 0 & 0 & 0 & 15 & 0 \\
\hline & $\begin{array}{c}\text { Full } \\
\text { interior }\end{array}$ & 0 & 0 & 0 & 18 & 0 & 25 & 0 & 0 & 0 & 24 & 0 & 0 \\
\hline B & Exterior & 0 & 0 & 0 & 24 & 0 & 0 & 0 & 24 & 0 & 0 & 0 & 24 \\
\hline $\mathrm{C}$ & Exterior & 0 & 0 & 0 & 12 & 0 & 0 & 0 & 12 & 0 & 0 & 0 & 12 \\
\hline $\mathrm{D}$ & Exterior & 0 & 0 & 0 & 3 & 0 & 0 & 0 & 3 & 0 & 0 & 0 & 3 \\
\hline$E$ & Exterior & 0 & 0 & 0 & 3 & 0 & 0 & 0 & 3 & 0 & 0 & 0 & 3 \\
\hline $\mathrm{F}$ & Exterior & 0 & 2 & 0 & 0 & 0 & 2 & 0 & 0 & 0 & 2 & 0 & 0 \\
\hline \multicolumn{2}{|r|}{ Total } & \multicolumn{4}{|c|}{119} & \multicolumn{4}{|c|}{$\mathrm{c}$} & \\
\hline
\end{tabular}

Based on Table 1 it is known that the first scenario produces 119 UPS with the selected angle for area A, B, C, D, E is $90^{\circ}$ and at zone $\mathrm{F}$ the selected angle is $45^{\circ}$. The second scenario produces 94 UPS with the selected angle for area A on the full exterior row, full interior, and the exterior in a row is $30^{\circ}, 45^{\circ}$, and $60^{\circ}$ angles, Area B, C, D and E selected $90^{\circ}$ angle and Area $\mathrm{F}$ is $45^{\circ}$. The third scenario produces 97 UPS with the selected angle for area $\mathrm{A}$ on the full exterior row and the full interior. Area $\mathrm{F}$ is $45^{\circ}$ angle while on the exterior row is the angle of $60^{\circ}$, Area B, C, D, and E the selected angle is $90^{\circ}$.

\section{Conclusion}

There are three proposed parking layouts for the SBA Mall parking lot, the first scenario generates 119 UPS, the second scenario generates 94 UPS and the third scenario generates 97 UPS. The results of this study can be an evaluation for SBA Mall, that if the company wants to optimize the parking capacity but with difficult maneuvers for riders then scenario 1 can be selected, but if the SBA Mall wants to facilitate visitors in maneuvering the parking lot but with less capacity, then alternative 2 and 3 can be selected.

In this paper, the validation of optimization result has not been done yet to determine whether the result of ILP model is in accordance with the condition of 
layout. In addition, this study also does not consider the effect of angle on the amount of vehicle maneuvering time, it is expected that further research also consider vehiclemaneuvering time. In addition, ILP model will ensure the resulting solution is the optimal solution but produces a long computational time. Therefore, further research can use other optimization methods such as heuristic or metaheuristic for faster computation time.

\section{References}

1. S. Abdelfatah, A., and A. Taha, M. Journal of Traffic and Logistics Engineering 2 (2014)

2. Asphalt Paving Association of IOWA. Asphalt Design Guide, College Park, Mary Land (1998)

3. G. M. Nasira, S. A. Kumar and T. S. S. Balaji. International Journal of Computer Applications 1 (2010)

4. Direktur Jendral Perhubungan Darat, Pedoman Teknis Penyelenggaraan Fasilitas Parkir, Departemen Perhubungan, Jakarta. (1998)

5. R. Setiawan. Faktor-faktor yang Mempengaruhi Kemudahan Manuver Parkir (Studi Kasus Universitas Kristen Petra). Konferensi Nasional Teknik Sipil, 1-10 (2008)

6. R. D. M. Bingle, and W. Oostendorp. Journal Math Modelling 9 (1987)

7. Lingo. LINDO Systems Inc (2017) 